\title{
Unanswered ethical and scientific questions for trials of invasive interventions for coronary disease: The case of single vessel disease Samer Jabbour*1,2, Shmuel Ravid ${ }^{2}$ and Bernard Lown ${ }^{3}$
}

\author{
Address: ${ }^{1}$ Faculties of Health Sciences and Medicine, American University of Beirut, Beirut, Lebanon, ${ }^{2}$ Lown Cardiovascular Center, Brigham and \\ Women's Hospital, Harvard Medical School, Brookline, MA, USA and ${ }^{3}$ Lown Cardiovascular Center, Harvard School of Public Health, Brookline, \\ MA, USA \\ Email: Samer Jabbour* - sjabbour@aub.edu.lb; Shmuel Ravid - sravid@partners.org; Bernard Lown - belown@comcast.net \\ * Corresponding author
}

Published: 29 March 2004

Current Controlled Trials in Cardiovascular Medicine 2004, 5:2

This article is available from: http://crm.controlled-trials.com/content/5/I/2

(C) 2004 Jabbour et al; licensee BioMed Central Ltd. This is an Open Access article: verbatim copying and redistribution of this article are permitted in all media for any purpose, provided this notice is preserved along with the article's original URL.
Received: 21 December 2003

Accepted: 29 March 2004

\begin{abstract}
Trials in the 1990s demonstrated that medical therapy is as effective as invasive therapies for treating single-vessel coronary disease. Yet more recent studies enrolling patients with this condition have focused on evaluating only invasive approaches, namely, stenting versus coronary artery bypass surgery. Several ethical and scientific questions remain unanswered regarding the conduct of these later trials. Were they justified? Why wasn't a medical therapy arm included? Were subjects informed about the availability of medical therapy as an equivalent option? Was optimized medical therapy given prior to randomization? The absence of clear answers to these questions raises the possibility of serious bias in favor of invasive interventions. Considering that medical therapy is underutilized in patients with coronary disease, efforts should focus more on increasing utilization of medical therapy and proper selection of noninvasive interventions.
\end{abstract}

\section{Introduction}

Two recent (2002) trials of surgical vs. percutaneous interventions for coronary disease $[1,2]$ raise serious questions about the conduct of research that focuses on management of coronary artery disease [CAD]. In both of these studies, symptomatic patients with proximal left anterior descending [LAD] stenosis - supposedly the stenosis site associated with the highest risk - experienced similar outcomes with stenting or with minimally invasive bypass surgery. These results leave the impression that physicians now have several properly validated invasive options from which to choose when treating patients with singlevessel CAD. This misleading perception ignores previous research on the efficacy of medical therapy in treating this condition, thereby casting doubt upon the ethical and scientific merits of these trials.

Unanswered questions in light of prior research In the 1990s, two well-designed trials compared medical and invasive approaches for treating single-vessel CAD. In the ACME study, death and infarction rates were similar with either medical therapy or with angioplasty, although angioplasty was associated with greater relief of angina [3]. The landmark MASS study focused on patients with high-grade proximal LAD stenosis [4]. Again, rates of death or infarction as well as abolition of limiting angina were similar with medical therapy, angioplasty or bypass surgery. 
In the 2002 trials, one of which received funding from industry, subjects were randomized to either stenting or to minimally invasive bypass surgery [2] (a medical therapy arm was not included). Several questions remain unanswered regarding the ethical justification for conducting these later trials. Were they really needed? Didn't the 1990 trials already demonstrate the equivalence of medical and invasive approaches for treating single-vessel CAD, including proximal LAD stenosis? The fact that we now have new invasive techniques is not per se sufficient reason for new trials to be conducted without concrete evidence that these techniques actually save more lives and prevent more infarctions. The populations studied were low risk by virtue of having chronic stable angina and normal left ventricular function. These cohorts would have done well on medical therapy. Why was medical therapy excluded from comparison? It seems that investigators had already decided that medical therapy was not as effective as the invasive strategies. Did these investigators ever tell their patients that medical therapy was equivalent to invasive interventions, based on previous research? Without this information, patients would not have been truly informed about all effective treatment options, when asked to consider joining either of the 2002 trials. Furthermore, rates of cardiac death or myocardial infarction were $3-6 \%$ with stenting and $6-10 \%$ with bypass in the recent studies. These rates are higher than those reported in the 1990 studies or in recent trials of aggressive lipid-lowering agents in similar populations [5]. Therefore, the risks associated with the proposed invasive approaches cannot be assumed to be minimal.

There are also unanswered scientific questions regarding the more recent studies. Why wasn't intensive and tailored medical therapy tried before proceeding to randomization? Instead of committing valuable resources to conduct trials of newer and more costly interventions, efforts should focus on ensuring that everyone with CAD, especially those with limited access to health care, receives appropriate medical treatment. What was the medical therapy strategy after interventions? Aggressive medication use and risk factor modification could have reduced the relatively high event rates observed post-intervention in these trials, and may well have obviated the need for invasive interventions in the first place.

Another concern relates to the need for coronary angiography. Neither study describes the presence and severity of ischemia. Diegeler et al. do not even mention level of angina or use of anti-anginal medications prior to referral. Why were patients referred for angiography in the first place? It is probably too late to contemplate whether medications or revascularization is better once high-grade stenoses are detected. The interventionist almost always recommends "doing something". The treating physician, who commonly underestimates the efficacy of medications and overestimates the value of interventions, [6] is under pressure to follow the recommendation. The patient, who senses grave danger when hearing $90 \%$ or 95\% stenosis (especially when coupled with the doctor's own anxiety), has no alternative but to "choose" an intervention. This is the path through which coronary angiography becomes a funnel for subsequent revascularization. Medical therapy has no chance here.

\section{Favoring invasive approaches to CAD: Evidence from other settings}

Investigator preference of invasive interventions over medical therapies for single-vessel CAD seems to extend to management of CAD in general. Several recent publications illustrate our case. The investigators of two recent studies favored invasive approaches to CAD in the elderly, despite outstanding results with medical therapy. In the TIME study, medically treated patients had slightly less overall risk of death and experienced no significant increase in risk of myocardial infarction after 6 months of therapy compared to those treated invasively, a remarkable finding considering that $31 \%$ of subjects had class IV angina [7]. Reassuringly, participants in both treatment arms experienced reduced angina and improved quality of life to a similar extent, while clinical events remained comparable at 1 year [8]. Similarly, Graham et al. [9] observed comparable outcomes with medical and invasive therapy among elderly patients. Why the authors of both studies chose to overstate the benefits of an invasive approach based on their own findings escapes us. [10] A balanced commentary justifiably questioned whether medical therapy was really optimal in these studies, but it failed to recommend optimizing medical therapy, which evidence already supports as the primary course of action in elderly patients with stable CAD [11].

Similarly, the debate over invasive vs. non-invasive therapy for acute coronary syndromes [ACS] exposes serious biases in favor of invasive therapy. Although a report of the RITA 3 trial found similar rates of death and myocardial infarction with both approaches, it overstated the benefits of invasive therapy in reducing refractory angina [12-14]. Certainly, patients with refractory symptoms need revascularization, but the exception should not become the rule. Given the equivalent effects of medical and invasive interventions on clinical events, the latter should be reserved for certain situations, e.g., for patients who are refractory to maximal medical therapy or for those with high risk indicators. An early invasive strategy for everyone with ACS makes no scientific, ethical, or economic sense. 


\section{Towards an alternative approach}

It is the process leading to coronary angiography where we most need to focus in order to improve care and prevent unnecessary interventions. In the absence of high-risk indicators, maximal, intensive and tailored medical therapy, coupled with aggressive risk factor modification, should be the first choice of action. The provocation of mild-to-moderate ischemia or angina in patients taking submaximal doses of medications is not an adequate indication for coronary angiography. By the same token, when coronary angiography is performed, and single-vessel CAD stenosis is detected, the first question that should come to mind is not which invasive intervention is better but whether medical therapy has been given a fair chance. There is ample evidence in the medical literature that this more conservative approach is not being followed properly [15]. The recent trials provide no new information that would lead us to disregard medical therapy as an effective and safe option for treating the patient with proximal LAD stenosis. On the contrary, the burden of proof is still on those advocating an invasive approach. If patients are told that an invasive approach is no more effective than medical therapy in preventing death or infarction or in abolishing limiting angina (and that medical intervention might even lead to more anginal relief), how many patients would still choose to undergo interventions that are costly and not free of complication? In addition, improvement in medical therapies since the two 1990 studies were published means potentially more benefits using a more conservative approach.

At a time when more studies are showing benefits of grossly underutilized medical therapies, we need to reevaluate the current processes of peer review of studies of invasive management of CAD by research funding agencies and scientific journals. The purpose here is not to make adversaries but rather to detect subtleties that can uncover biases and correct them for the benefit of both patients and science. This is the only way for us to find balanced approaches for management of CAD. We encourage everyone to think together of more effective mechanisms than the occasional letter to the Editor.

\section{References}

I. Diegeler A, Thiele H, Falk $V$ et al.: Comparison of Stenting with Minimally Invasive Bypass Surgery for Stenosis of the Left Anterior Descending Coronary Artery. N Engl J Med 2002, 347:56I-566.

2. Drenth DJ, Winter JB, Veeger NJ et al.: Minimally invasive coronary artery bypass grafting versus percutaneous transluminal coronary angioplasty with stenting in isolated high-grade stenosis of the proximal left anterior descending coronary artery: six months' angiographic and clinical follow-up of a prospective randomized study. J Thorac Cardiovasc Surg 2002, 124:130-5.

3. Parisi AF, Folland ED, Hartigan P: A comparison of angioplasty with medical therapy in the treatment of single-vessel coronary artery disease. $N$ Engl J Med 1992, 326: I0-6.

4. Hueb WA, Bellotti G, de Oliveira SA et al.: The Medicine, Angioplasty or Surgery Study [MASS]: a prospective, rand- omized trial of medical therapy, balloon angioplasty or bypass surgery for single proximal left anterior descending artery stenoses. J Am Coll Cardiol 1995, 26:1600-5.

5. Pitt B, Waters D, Brown W et al:: Aggressive lipid-lowering therapy compared with angioplasty in stable coronary artery disease. N Eng J Med 1999, 341:70-76.

6. Poses RM, Krueger JI, Sloman S, Elstein AS: Physicians' Judgments of Survival After Medical Management and Mortality Risk Reduction Due to Revascularization Procedures for Patients With Coronary Artery Disease. Chest 2002, 122:122-133.

7. The TIME Investigators: Trial of invasive versus medical therapy in elderly patients with chronic symptomatic coronary artery disease [TIME]: a randomised trial. Lancet 200I, 358:95I-957.

8. Pfisterer M, Buser $P$, Osswald $S$ et al.: Outcome of elderly patients with chronic symptomatic coronary artery disease with an invasive vs optimized medical treatment strategy: one-year results of the randomized TIME trial. JAMA 2003, 289:1 II 7-23.

9. Graham MM, Ghali WA, Fari PD et al: Survival after coronary revascularization in the elderly. Circulation 2002, 105:2378-2384.

10. Jabbour S, Ravid S: New candidates for promoting coronary revascularization: The elderly. Circulation 2003, 107:e26.

II. Peterson ED: Patient-centered cardiac care for the elderly: TIME for reflection. JAMA 2003, 289: I I 57.

12. Fox KAA, Poole-Wilson PA, Henderson RA, for the Randomized Intervention Trial of unstable Angina [RITA] investigators* et al: Interventional versus conservative treatment for patients with unstable angina or non-ST-elevation myocardial infarction: the British Heart Foundation RITA 3 randomised trial. Lancet 2002, 360:743.

13. Wallentin L: Non-ST-elevation acute coronary syndrome: fuel for the invasive strategy. Lancet 2002, 360:738-739.

14. Massel $D$ : Management of unstable coronary-artery disease. Lancet 2000, 355:573.

15. Carasso S, Markiewicz W: Medical Treatment of Patients with Stable Angina Pectoris Referred for Coronary Angiography: Failure of Treatment or Failure To Treat. Clin Cardiol 2002, 25:436-44I.

Publish with Bio Med Central and every scientist can read your work free of charge

"BioMed Central will be the most significant development for disseminating the results of biomedical research in our lifetime. "

Sir Paul Nurse, Cancer Research UK

Your research papers will be:

- available free of charge to the entire biomedical community

- peer reviewed and published immediately upon acceptance

- cited in PubMed and archived on PubMed Central

- yours - you keep the copyright

Submit your manuscript here:

http://www.biomedcentral.com/info/publishing_adv.asp

BiolMedcentral 